\title{
Promoting CLT within a Computer Assisted Learning Environment: A Survey of the Communicative English Course of FLTC
}

\author{
Md. Zulfeqar Haider ${ }^{1} \&$ Takad Ahmed Chowdhury ${ }^{2}$ \\ ${ }^{1}$ Foreign Language Training Center, Ministry of Education, Dhaka, Bangladesh \\ ${ }^{2}$ University of Asia Pacific (UAP), Dhaka, Bangladesh \\ Correspondence: Takad Ahmed Chowdhury, Department of English, University of Asia Pacific, House \# 8/A, \\ Road \# 7, Dhanmondi, Dhaka-1205, Bangladesh. Tel: 88-02-967-3057 (Extn.117).E-mail: takad@uap-bd.edu
}

\author{
Received: April 19, 2012 Accepted: May 10, 2012 Online Published: July 3, 2012 \\ doi:10.5539/elt.v5n8p91 URL: http://dx.doi.org/10.5539/elt.v5n8p91
}

\begin{abstract}
This study is based on a survey of the Communicative English Language Certificate (CELC) course run by the Foreign Language Training Center (FLTC), a Project under the Ministry of Education, Bangladesh. FLTC is working to promote the teaching and learning of English through its eleven computer-based and state of the art language laboratories. As Computer Assisted Language Learning (CALL) is becoming increasingly popular in many EFL/ESL contexts, the fully computer based language teaching facilities offered by FLTC can be seen as a significant step towards implementing CALL in the soil of Bangladesh. However, any language course using technology alone may not always ensure the best practices of language teaching and learning; the advantages of technological advancements are to be adapted according to the pedagogic needs of the concerned language course. This paper, therefore, seeks to explore how aspects of CALL are being integrated within a framework of Communicative Language Teaching (CLT). The survey was conducted on 425 learners who had completed the CELC course at the selected four centers of FLTC. This study provides a brief overview of how computers are being used for teaching communicative English. It is found that the trainees gave a positive response about the contents, facilities, and organization of the course but not completely satisfied with the teaching techniques and participants' role as independent learners. It is recommended that there is a need for making the computer based learning materials more accessible to the learners so that they can use them more independently in and outside the language lab.
\end{abstract}

Keywords: Bangladesh, CLT, CALL, FLTC, learner autonomy, teacher's role

\section{Introduction}

\subsection{An Introduction to the Study}

The emergence of Computer Assisted Language Learning (CALL) has led to significant changes in the arena of language teaching and learning starting from the use of innovative learning materials to the widening of interaction patterns among a huge and diverse community of learners. There have been arguments regarding the advantages and disadvantages of CALL, though the trend of using computer assisted devices in language teaching is increasing worldwide. It is obvious that the success of a language teaching course depends not only on the technological aspects it incorporates but also on many other factors including the pedagogic features. Hence it is important to consider the introduction of technology in a language teaching program in terms of the "pedagogical needs that the technology is actually fulfilling" (Littlemore, 2002). The evaluation of any teaching program depends on whether it influences the way participants think about a subject, causes participants to change their behaviour, and leads to some meaningful and substantial developments in certain skills areas. These can be best measured by collecting responses of the learners who are supposed to be the ultimate beneficiaries of the program. As the CELC of FLTC aims at developing learners' basic communicative competences in English within the computer assisted learning environment of its language laboratories, this survey is designed to gather information on how well the course objectives have been achieved and what factors might impede the successful achievement of the targeted learning outcomes of the course.

\subsection{Objectives of the Study}

The main objectives of this study are: 
- $\quad$ To conduct an evaluation of the Communicative English Course of FLTC with special focus on the elements of CALL,

- To identify the pedagogical issues to be considered in using computers in communicative classroom,

- $\quad$ To generate feedback for developing and revising the course content, format and mode of teaching,

- $\quad$ To provide a base for the EFL teaching communities to anticipate the prospect of CALL in the context of Bangladesh and other developing countries.

\subsection{Previous Studies}

There is only a small amount of published research focusing on the relationship between CLT and CALL in the context of Bangladesh. The issue of effective use of mobile and multimedia technology in developing countries has been discussed by Deb (2000) who observes that successful use of technology does require not only 'the installation and application of systematized knowledge' (p. 35) but also the 'implied knowledge of the contextual environment in which it is to be used'. In another study Deb (2012) examines certain instances of using telephone, photography, audio, video, internet, eBook, animations etc. for delivering effective distance education in developing countries, including Bangladesh. Begum (2011) explores the potential of using technology while focusing on the use of mobile phones in the undergraduate EFL classrooms in Bangladesh. In a recent study that explores the views of academicians and students on ICT-based higher education in Bangladesh, Hoque and Alam (2010) have found that students prefer the flexibility in the learning process through ICT-based education to rigid and more traditional use of textbook materials. They, however, argue that 'a very high level of integrity and moral standard is required by instructors, ICTs experts, students and other stakeholders' (p. 101) for successful implementation of ICT based education system in a country like Bangladesh. A study by Mahruf and Kirkwood (2012) reveals the implications of using i-Pod based multimedia teaching resources by the Bangladeshi secondary teachers to support teaching and learning.

Though the above studies have partial relevance to the current topic of research, they do not fully address the issue of promoting CLT in a CALL setting in the teaching-learning context of Bangladesh. The present study looks at the teaching of English solely from the perspective of CLT approach which puts emphasis on developing the four skills of learners through meaningful and interactive use of the target language. It is true that CLT is already a much talked issue in Bangladesh. However, the question of using technology in promoting CLT has not received much attention by the researchers yet. When the government of Bangladesh has set the target of achieveing digital revolution in all sectors by 2021, the issue of integrating CALL to the successful implementation of CLT in Bangladeshi EFL classroom becomes very pertinent. Therefore, this study aims to look at the relationship between CLT and CALL and hopes to identify significant implications for the education sector of Bangladesh and other developing countries with the same aspirations.

\subsection{Literature Review}

\subsubsection{An Introduction to CLT}

CLT is an umbrella approach to language teaching which is essentially progressive in nature. It originated in the UK in the 1960s (Wright, 2000). In CLT "The heart of the language lesson is the communicative activity itself (Howatt, 1984: 279). The idea of communicative language teaching emerged in the 1970s following Hymes' (1972) theory of communicative competence, which greatly emphasized learners' ability to use language in context, particularly, in terms of 'social demands of performance' (McNamara, 2000: 116). Hymes believes that knowing a language is more than knowing its rules. Once Hymes proposed the idea of communicative competence, it was expanded in various ways during the following two decades. The term competence was interpreted in many different ways by researchers. To some it simply means the ability to 'communicate'; to others it means the social rules of language use; and to yet other, it refers to a set of abilities including knowledge of linguistics, socio-linguistics and discourse rules (Bachman \& Palmar, 1984: 34).

Hence, the dimensions of communicative competence which are identified in the literature include: linguistic or grammatical competence, sociolinguistic or pragmatic competence, discourse competence, strategic competence (Richards \& Rogers, 1986; and Hedge, 2000), and fluency (Hedge, 2000). Communicative Language Teaching is best considered as an approach rather than a method (Richards \& Rogers, 1986). However, the basic idea of communicative competence remains the ability to use language appropriately, both 'receptively and productively, in real situations' (Kiato, et al. 1996: 1).

A communicative syllabus consists of a series of activities organized round some central principles which concentrates on 'use' rather than 'usage' and is fluency-focused rather than simply accuracy-focused (Widdowson, 1978, Littlewood, 1981). The kinds of communicative tasks to be used by learners in a CLT lesson 
have a focus on tasks to be achieved through the language rather than exercises on the language. It emphasizes on students' initiatives and interactions rather than teacher-centred interactions (Maley, 1986: 86). It is also argued that CLT does not intent to ensure the purely 'linguistic' competence of learners that is concerned with the tacit knowledge of language structure. It is concerned with linguistic performance, a process related to encoding and decoding a language (Hedge, 2000). CLT also aims at integration of skills rather than isolation (Widdowson, 1978, Littlewood, 1981, Hedge, 2000) and it has an awareness of variation in language use rather than attention to the language (Trudgill \& Hannah, 1983). It is evident from the relevant research that the goal of communicative teaching is to develop an ever-improving capability to use English to communicate with others and to develop and apply 'an-increasing understanding of how English is organized, used and learned' (Clark et. al. 1994: 37).

\subsubsection{The Concept of CALL and 'Communicative' CALL}

There is a vast body of literature dedicated to the discussions of the background, emergence and current considerations of CALL. CALL stands for Computer Assisted Language Learning, a term used by teachers and students to describe the use of computers as part of a language course (Hardisty \& Windeatt, 1989). Gunduz (2005: 197) defines CALL as a means of 'presenting, reinforcing and testing' particular language items. Jones \& Fortescue (1987) indicate that the traditional description of CALL is unfortunate and they present the computer as flexible classroom aid, which can be used by teachers and learners, in and out of class, in a variety of ways and for a variety of purposes. Warschauer (1996) discusses the three important phases of CALL- behaviorist, communicative and integrative CALL. The communicative CALL was based on the communicative approach to teaching English. The concept of incorporating the principles of communicative language teaching approach within the CALL framework was pioneered by John Underwood. He identifies the 'Premises for 'Communicative CALL' (Underwood, 1984: 52). According to him communicative CALL

- focuses more on using forms rather than on the forms themselves;

- teaches grammar implicitly rather than explicitly;

- allows and encourages students to generate original utterances rather than just manipulate prefabricated language;

- does not judge and evaluate everything of the students nor reward them with congratulatory messages,

- avoids telling students they are wrong and is flexible to a variety of student responses;

- uses the target language exclusively and creates an environment in which using the target language

- feels natural, both on and off the screen; and

- will never try to do anything that a book can do just as well

The concept of communicative CALL has called for various forms of pedagogic awareness within the computer assisted language classrooms. It stresses on the interaction patterns actually produced by learners through the use of software or other forms of electronic materials. The new body of research in communicative CALL calls for planning the language teaching programs that takes the target interaction as its starting point (Seedhouse, 1995).

\subsubsection{The Communicative English Course of FLTC}

This is a pre-intermediate course for young people willing to take jobs in and outside Bangladesh. The course aims at helping the learners develop a workable level of proficiency in English language use. The course mainly focuses on the development of the four skills - listening, speaking, reading and writing in English for communicative purpose. The following is a summary of the CEL course offered by FLTC in its 11 language laboratories based on the Communicative English Training Manuel (2009) of FLTC.

The course aims to enable the learners to:

- Read and understand simple texts in English

- Write simple notes and messages with a reasonable amount of accuracy;

- Understand English spoken in various or every day situation;

- Speak English for day to day communication and interactions

- Develop an acceptable level of accuracy in grammar.

Entry requirements: Candidates willing to enroll in the course are required to have proven elementary level of proficiency in English. Academically, candidates must have passed at least Secondary Certificate examination. Candidates are selected through a placement test. The placement test is prepared by ELT specialists. 
Delivery of course: This course is of 72 hours duration including two tests one in the middle and the other at the end of the course. The participants have 72 contact hours in the language laboratory where they are supposed to have direct exposures to the use of English through real life and meaningful practice activities.

Materials used: The course is delivered via a course book specially prepared by the expert trainers of FLTC as well as renowned ELT course writers of the country. The book is available in both printed and electronic (PDF) forms. The course book is divided into four modules, each focusing of one of the four macro skills e.g. listening, speaking, reading and writing. However, some other books and audio-video CDs published by international publishers and materials downloaded from the internet are also used by the trainers to achieve the targeted course objectives. The list of such books includes the following:

Assessment of learners: There are two tests -a mid-course test and a final exam at the end of the course. The mid test is given after 36 hours of teaching and the final test after 72 hours of teaching. The mid-course test is of 1 hour duration and has questions on Reading, Writing and Communicative Grammar only. The two hour long final exam consists of questions on Reading, Writing, Communicative Grammar, Listening and Speaking. The learners have to face a viva voce board as part of their speaking test. There are 10 marks for attendance and classroom performance. The learners are assessed in terms of four different grades, A+ $(80-100 \%$ marks $)$, A (70-79\% marks), B (60-69 \% marks) and P (Pass). The final test is prepared and administered under the supervision of the central monitoring cell.

Facilities available in training center: FLTC training rooms are richly equipped with state-of-the-art facilities. A specially designed software called 'Yo-Lang' is used to operate the computerized language laboratory where each student is connected to the main computer on his/or her own individual monitor. Besides the classroom furniture, the resources available in each training room are: Books (both hard and soft version), computer with internet connections, CDs, multimedia projector, headphones (one for each learner), white board, colour television set, DVD player, photocopier, and visual presenter. Each room is fully air-conditioned and there is alternative power system (e.g. generator or IPS) in each centre.

\section{Methods}

\subsection{General Methods of the Study}

The survey was conducted on the learners of the CELC course of FLTC project at its four training centers. The survey was administered by using questionnaires designed for the selected learners of the course. Some sources of secondary data such as the FLTC Course Manual, the syllabus document and teaching learning materials used in both printed and electronic formats have also been reviewed to help form a primary knowledge base to undertake the study.

\subsection{Data Gathering Tools}

A questionnaire was developed to collect learner's responses on various aspects of the CELC course. It included both close-ended and open-ended questions. For the close-ended questions, the participants were asked to respond to to 18 questions on a four to five point scale (see Anex.1). The questions were formulated to draw participants' responses on five major aspects of the training course- a) the course content, b) the course organization, c) the teaching and learning support, d) the course instructor and, e) overall evaluation. The open ended questions (questions 19-21) were included to generate some more substantial evidences of trainees' views on the three broadly defined areas of the training e.g., a) the strong areas of the course b) the limitations of the course and c) suggestions for improving the course. The questionnaire was first piloted with a small sample and then finalized for distribution among the respondents.

\subsection{Sampling}

Out of the eleven training centers of FLTC, four centers were selected on a purposively random basis. Data were collected from the four centers based at the four big cities of the country- Rajshahi, Chittagong, Comilla and Sylhet. All the learners available in the selected centers were included in the sample. A total of 425 learners took part in the survey. Out of them, there were 94 participants from Rajshahi, 128 from Sylhet 105 from Comilla and 98 from Khulna. There was a good balance of male and female participants in the sample size. The number of respondants varied from one center to another because of the different number of students enrolled in the respective centers at the time of the survey.

\subsection{Data Collection Procedure}

The selected centers were personally visited by the study team members on the day of final test of each course. Every learner was given out a questionnaire to complete and return it to a member of the study group. As the 
questionnaire was written in English, care was taken that the respondents understood each question.

\subsection{Data Processing}

The data collected through the questionnaire was compiled manually via hand tabulation. Then the compiled data was transferred to computer for analyzing them. No special statistical software was used. Microsoft Excel program was used for making simple calculations and generating charts. The open ended questions were all classified under some common headings first and then summarized as per the three main areas of search. Some of the representative remarks of the respondents have been directly quoted.

\subsection{Limitations of the Study}

The survey was conducted on the basis of learners' responses only because of time constraints and limitation of funds. Therefore, it was not possible to cross-check the responses of the learners with that of the others. It could be done so by interviewing some of the course trainers and by observing few lessons in each centre. Though the sample size was good enough for the small scale report, more learners from some other centers could be included.

\section{Results}

\subsection{Responses to the Close Ended Questions}

The evaluation consisted of questions based on a four to five-point response scale; the scale measures the degree the participants found suitable to their responses regarding a particular question about the course. The questions were formulated to draw the course participants' responses on five major areas of the training course such as, a) course content, b) course organization, c) Teaching and learning support, d) the course instructor and e) overall evaluation. A summary of the question by question responses are given below.

Question 1: How suitable was the course content for you?

In their response to this question, $44 \%$ reported the course content as suitable, $25 \%$ very suitable and $24 \%$ mostly suitable. Only $6 \%$ of the participants found the course as partly suitable and only $1 \%$ said it was not suitable. It is evident that in total $93 \%$ of the trainees reported that the course content was suitable, very suitable or mostly suitable. The findings illustrate a very strong aspect of the FLTC training course.

Question 2: How relevant were the topics covered during the course?

In their responses on the relevance of the topics covered during the course, $47 \%$ of the trainees reported the topics as relevant and $26 \%$ as mostly relevant. Another $15 \%$ trainees found the topics as very relevant while only $9 \%$ found them to be partially relevant. Only $1 \%$ said the course topics were not relevant and $2 \%$ did not respond to this question.

Question 3: How user-friendly were the digital contents for you?

A good majority of $52 \%$ of the trainees opined that the digital contents were user friendly to them while $26 \%$ found them partly difficult to handle. $13 \%$ trainees have reported the content as very easy to use contrary to the $7 \%$ trainees who considered the content difficult. However, a very small minority of $1 \%$ trainees found the contents too difficult. Overall, a majority of 78 percent trainees consider the course contents either easy or partly difficult though most of such contents were produced by the native speakers.

Question 4: Did the course progress logically from beginning to the end?

In question number 4 , the trainees were asked to comment on whether the course progressed logically from beginning to the end. In their response, a big majority of the trainees opined that the course always progressed logically. Another $28 \%$ reported that there was logical progression in the course for most of the time. Only $7 \%$ trainees said not always there were logical progression with $1 \%$ saying never was there a logical progression in the course.

Question 5: What were your objectives behind taking this course?

Participants were asked to tell about the reasons that led to their enrolment in the course. A huge majority of 230 trainees out of 425 (54\%) reported that they got enrolled in the course to develop their fluency in English. The second highest number of 121 respondents $(28 \%)$ also talked developing their competence in English as the reason to come to the course. Among other reasons 23 (6\%) mentioned getting job abroad and 37 (9\%) mentioned getting access to higher education. Only 3 trainees mentioned getting job locally as a reason.

Question 6: How much of your objectives have been achieved from the course?

Once the trainees have mentioned the reasons for enrolling to the course, they were asked how much of their 
expectations were fulfilled. In response to this question 50 trainees opined that the course helped them achieve their objectives very well. Another 36\% said it helped achieve the objectives mostly. Among others $10 \%$ reported that the course did not help them much with their expected outcome. Only $2 \%$ responded with the option 'not at all'.

Question 7: Was there a balance of lectures, group work and lab-based works in each lesson?

The respondents were asked to comment on if there was balance between the various activity types done during each lesson. In their response $63 \%$ trainees ticked in the 'yes, always' option. $25 \%$ trainees reported that there was a balance for most of the time. Only $7 \%$ respondents chose to tick on the 'not always' option.

Question 8: Were the course materials available?

As the trainees were asked to comment on the availability of course materials within the training centres of FLTC, they gave a very positive response. $63 \%$ of them said the materials were always available while $24 \%$ said they were available most of the time. However, $9 \%$ of the trainees opined that the materials were not always available.

Question 9: Were the course materials useful?

Once the participants were asked to comment on the availability of the materials, they were asked to give feed back on the usefulness of the materials. Here a sharp majority of $46 \%$ trainees reported the materials to be useful while another $26 \%$ found them to be very useful. However, a significant $20 \%$ of trainees said the materials were of 'some use' only. Among the rest, $3 \%$ said the materials were 'of little use' while $2 \%$ found them to be of no use.

Question 10: Was the presentation clear enough to understand?

Here again a huge percentage of trainees $(63 \%)$ responded that the presentation made during the lesson was always clear enough for them to understand. $28 \%$ said they were clear most of the time. A very small percentage (4\%) said the presentation was not always clear while $2 \%$ said it was never clear.

Question 11: Did you find interest in the course?

Responses: The participants were asked if they had found interest in the course. In response a big majority of $67 \%$ said they always found interest in the course. $26 \%$ said they find interest most of the time. Only $4 \%$ said they did not find interest always and $1 \%$ said they did never find interest in the course.

Question 12: Did the instructor encourage your participation in the class?

It is recommended in the course outline that a participatory approach in the classroom is to be followed in order to maximise the targeted outcomes of the course. In this respect, it is important for the instructors to encourage the learners to participate in activities. In response to the question whether the instructors encouraged the trainees to participant in the class, $63 \%$ reported they the instructors always did so. $18 \%$ said they were encouraged to participate most of the time. Among other respondents $8 \%$ and $6 \%$ said it was done sometimes and usually respectively. Only $3 \%$ reported they were never encouraged to participate.

Question 13: Was the instructor skilled in using the language lab/technology?

The FLTC training centers are equipped with very sophisticated electronic devices and the learning programme is fully computerized. Therefore there is a need for the instructors to be well skilled in operating the language lab and must have some IT skills. The responses reveal that $64 \%$ of the trainees always found that the instructors were skilled in using the lab while another $20 \%$ found the same for most of the time. This shows the strengths of the instructors in dealing with a state of the art modern language lab skillfully.

Question 14: Did the instructor show a good command of the course materials?

A vast majority of $59 \%$ trainees reported that the instructor always demonstrated a command of the course materials. Another 20\% said the instructors' command of the course materials was evident most of the time. Only $1 \%$ never noticed anything about the instructors' command of the materials. The rest responded in the affirmative but with varying frequency such as 'usually (6\%), and 'sometimes' (5\%).

Question 15: Overall, what do you think of the course content?

The trainees gave a very generous feedback on the overall quality of the course content. $54 \%$ of the trainees reported the course content as 'good' while $33 \%$ as 'very good'. Therefore, it is evident that $87 \%$ of the trainees thought that the course content was either good or very good. Nevertheless, $8 \%$ trainees found the course content of average quality and, $1 \%$ each said it was 'poor' and 'very poor'. 
Question 16: Overall, how well organized was the course?

As the trainees were asked to give their overall comments on how well organised the course was, $48 \%$ said the organization was good and another $38 \%$ said it was very good. Here again, it is seen that the trainees who found the organization of the course either good or very good comprise $86 \%$ of the total respondents. Among others, $9 \%$ reported the organization of the course as 'average' while $1 \%$ each found it was 'poor' and 'very poor'.

Question 17: What was the overall standard of teaching?

The trainees gave a generous feedback as they were asked to comment on the overall standard of teaching. In fact, $90 \%$ of the trainees reported that the standard of teaching was good or very good (good $44 \%$, very good $46 \%)$. Only $6 \%$ trainees found the quality of teaching of 'average' standard.

Question 18: What is your overall evaluation of the course?

The trainees were asked to do an overall evaluation of the communicative English course of FLTC. In their overall evaluation $35 \%$ trainees reported the course as very good and another $53 \%$ reporting 'good'. It is worth noticing that a total of $88 \%$ trainees evaluated the course as either a good or very good one. Only $8 \%$ said the course was of average standard. $1 \%$ termed the course as 'very poor' while another $1 \%$ saying 'poor'.

\subsection{Findings from Open Ended Questions}

The best way to demonstrate the benefit and impact of the CEL course is to let the participants speak for themselves freely. They were asked to give opinion on the strengths, limitations of the course as well as to suggest ways for improvement. The following consists of participants' responses to the open ended questions. To save space, similar comments made by more than one participant are rephrased and compiled.

Question 19: What is your opinion on the good side(s) of this course?

Most of the trainees made it clear that the teaching facilities and approach offered by FLTC is very good. Many of them mentioned that they used their learning to communicate more effectively in English in and outside the classroom. Some of the most representative comments made by trainees are quoted below.

a. It helps me increase my fluency. Conversation system is good. It made me interact with others in English. The instructors are very good. I can learn English very easily.

b. Learning English is easier in FLTC. Teachers are very helpful.

c. When I got admitted to the course, I could not speak and write in English very well. Now, I can speak and write easily with confidence.

d. We have some expert trainers here. They encourage us to speak of new things.

e. This course has greatly contributed to orient my language skills. The lab is fairly organized, teachers are friendly and helpful. Overall, the course is very suitable to learn a language easily.

f. This course helped students overcome their shyness and can speak fluently in front of others.

g. Listening to English songs and watching movies are the two things I enjoyed most.

h. The best side of FLTC training is its lab based practice with modern materials, CDs and videos.

i. I have improved my listening by using the listening CDs.

j. The course creates confidence among the learners.

k. We didn't feel any hesitation when we talked to each other.

1. The good side is here we have many listening and speaking tasks which is not available in our academic studies. It is very important to improve listening and speaking to learn a language.

m. I liked the English speaking environment of FLTC.

Question 20: What according to you are the limitations of the course (if any)?

Responses: While asked about the limitations of the course, most trainees did not specify many points. A good number of trainees reported that there were no limitations at all. However, some of them mentioned few problems related to physical facilities and technical support. For example, the problem caused by faulty headphones was mentioned by some trainees. However, the most serious concern voiced by the trainees in general is the problem of load shedding. Moreover, being in a very high tech lab, the trainees were also irritated by few other technical hazards. Some of the comments were as follows:

a. Headphone was not working, and it was disturbing. 
b. Poor students can't grasp many things as they are poor in grammar.

c. There is no language clubs in the centre.

d. There is no $\mathrm{CD}$ for taking home.

e. FLTC needs some active instructors. Without an active instructor, it is not possible to develop the learners.

f. Only one instructor for the whole course.

g. Content is not enough to cover the communicative skills

h. No self access centre for further practice.

Question 25: Please give your suggestions on how to improve this course.

Most of the suggestions given by the participants reflect some common concerns as well as expectations about the CELC course. Though it is evident that all the learners received some benefits from the course, they gave suggestions for further improvement of the course. The suggestions were as diverse as the students themselves. This is not surprising in a course that deals with learners coming from a wide variety of backgrounds and needs. They suggestions are as follows:

a. Class time is limited (too short). Manual could be improved.

b. Need language clubs for more practice.

c. There could be some special course for weaker students.

d. We need atleast 40 minutes of conversation practice.

e. Grammatical items could be included in the manual.

f. A separate moderator is needed to run a language club.

g. Uninterrupted power supply is essential.

h. There should be some more books other than the prescribed manual.

i. More issues of culture and manners could be included in the course book. More topics like 'In a coffee shop', 'In a railway station' could be added.

j. Instead of sitting at the front, the instructor should help the students while they are talking in pairs.

k. After the course students can be given out some materials to practice at home, e.g listening CDs.

1. Writing skills need to be given importance alongside speaking and listening.

\section{Discussions}

The results of the survey clearly indicate that the Communicative English course of FLTC has many strong areas which are as follows.

\subsection{Evaluation of Course Content}

Most learners found the course content suitable and relevant and easy. It is also encouraging to find that there is a logical progress of the course contents. The course content is found to be suitable and relevant in terms of the learners' expectation and needs which are reflected in questions 5 and 6 . It is interesting to know that a vast majority of learners expected to develop their English language skills and competences from the course. As 50\% trainees clearly mentioned that the course helped them achieve their objectives very well and $36 \%$ said it helped achieve the objectives mostly, the testimony of the suitability and relevance of the course becomes obvious. However, it is worth noticing that a small percentage of trainees found the course partly suitable and relevant. Therefore, though the course content is generally reported to be suitable and relevant, there are still scopes for further development. One important area of concern is the question of balancing the level of difficulty. In fact, the Communicative English Language Certificate course of FLTC is offered to a wide variety of target learners and it is difficult to set a common level of difficulty for all the learners. It is suggested by some trainees in the open ended section of the questionnaire that the course can be divided into several modules based on levels of difficulty.

\subsection{Evaluation of Course Organization}

The course is reported to be well organized by a sharp majority of trainees. The organization of the course is looked at from the perspectives of the clarity of course objectives and the balance of various activity types within the course. The findings in this area are also quite positive. However, measures can be taken to allow more practice opportunities for learners during the course. This is also suggested by the trainees in their reply to the 
open ended questions.

\subsection{Teaching and Learning Support}

The findings in this area are also encouraging. It was reported by the majority of trainees that the course materials were available as well as useful. But it was a bit of a concern for $20 \%$ of the trainees who found the materials 'of some use' only. This finding indicates that there are still scopes for revising the course materials in terms of their usefulness. The issue of teaching and learning support is also looked at from the perspectives of getting feedback by learners, clarity of presentation and finding interest in the course. Again, a more than $60 \%$ of the learners are with the view that they got regular feedback during the course. About the clarity of presentation, the trainees gave a very positive feedback as $63 \%$ of them have always found the presentation clear. It is a real challenge for any language learning course to make it useful as well as interesting. However, there has to be a balance of these two in any good language learning course. It is evident that there is a good combination of instructive as well as interesting features in the Communicative English course of FLTC. What is more satisfying is a huge majority of $92 \%$ trainees found the course interesting either 'always' or 'most of the time'.

\subsection{Evaluation of Course Instructor}

The instructors are evaluated by the learners on their certain performance. One of the findings about the instructors is they have a combination and good skills, knowledge and attitudes. Instructors' skills of using the labs and their command of the subject are essential qualities for any successful course. The findings confirm the high level of skills and knowledge of the FLTC course instructors. Moreover, it is found that the instructors are helpful and supportive too. It is evident from the open ended responses that the instructors were helpful, encouraging and motivating to majority of the learners. However, in response to question no. 15, some $7 \%$ trainees reported that they never got any clear answers from the instructor. However this view, despite held by a small percentage of learners, may not be ignored as an instructor must ensure that all the learners get satisfactory answers to all their queries. Similarly, answers to questions 17 and 18 reveal that majority of trainers' skills and knowledge for most of the time while only $20 \%$ said always. This is again another alarming finding. Though the responses reflect a positive picture, there are still scopes for improvement. Particularly, the instructors must be skilled in operating the language labs and they must have a thorough command over the multimedia based materials.

\subsection{Overall Evaluation of the Course}

In their overall comments about the course most of the trainees reported that the course was quite up to the standard in terms of the course content, organization, teaching quality and teaching and learning support. The positive comments far outnumbered the negative comments. However, some participants wanted more tests during the course to review their progress, and some felt that the initial sessions were not organized as efficiently as could be. Moreover, there were 6-7\% trainees who found the course of average standard. These suggest that there are still scopes for improving the course and making it more interesting as well as useful to the learners.

Overall, the trainees gave a very positive response about the contents, facilities, and organization of the course but still not completely happy with the teaching and organization. Particularly, it is pointed out that teachers have to think about making themselves accessible to the learners even outside the classroom and build a rapport with the trainees.

\subsection{Recommendations}

The following recommendations emerge from synthesis of the results of this survey and discussions. These recommendations are meant to be considered alongside the other components of this report. It is hoped that they will provide the FLTC authority, trainers, course designers and concerned decision taking bodies with a framework for moving forward. The maintenance of current monitoring practices is also necessary for the continued establishment of baseline data. Factors that need to be addressed in the future include:

a. Revision of the current Training Manual with inclusion of more topics for practicing English in real life situation.

b. Re-designing of the course to cater the needs of weaker participants. This can be done by the dividing the course in different levels- pre-intermediate, intermediate and advanced.

c. Establishment and functioning of self-learning center with internet facilities in each training centre.

d. Creating more opportunities for learners to have conversation practice among them.

e. Inclusion of communicative grammar practice activities in the class. 
f. Providing learners with more self access materials with interactive CD ROMs.

g. Incorporating issues of English culture within the course by using English movies and documentaries.

h. Ensuring the continuous professional development of the instructors through training, mentoring and action research.

i. Enhancing instructors' IT skills for operating the language labs and dealing with the audio vosual materials more confidently.

j. Increasing logistic supports for learners that include uninterrupted power supply, high speed internet connectivity and using cell phones based networking system.

k. Conducting more tests for learners during the course so that they can know about their progress as well as difficulties. These tests could be conducted online.

\section{Conclusion}

English language teaching and learning has now become an essential factor of the overall development agenda of Bangladesh. Though there have been endless debates on the various methods and approaches to teaching English while using technology, there are still some common set of criteria which can help evaluate the success of a communicative language teaching program. While evaluating the CELC course of FLTC, some key factors such as the course content, organisation, teaching learning support and quality of teaching were taken in to account. According to these parameters, the CELC course of FLTC is reported to be a successful and popular course among its learners. On the basis of the findings it can be recapitulated that the FLTC project is doing a creditable job by providing quality English language teaching using Computer Assited Language Learning (CALL) facilities to the learners of Bangladesh.

The study, in all the areas of queries, found strong evidence of satisfaction from the learners of the course. In their overall comments about the course a huge majority of the trainees reported that the course was quite up to the standard in terms of the course content, organization, teaching quality and teaching and learning support. In each response area, the positive comments far outnumbered the negative comments. The course evaluation shows that the CELC course provided the participants with knowledge and skills that they were able to apply in order to communicate in English in familiar situations. It is worth mentioning that the participants reported the course not only as useful but also as enjoyable. Thus, the findings of the report substantiate the innovativeness of CEL course as well as ascertain the utility of CALL for the purpose communicative language learning.

This study also reveals some areas of weaknesses regarding program delivery, teaching approaches and learning support. Some of these problems are not unexpected as the program was still evolving and experiencing the changing practices during the study. These resulted in some of the instructors' difficulty in getting themselves at ease with the computer based materials and technological devices quickly.

Moreover, for a communicative language teaching course like CELC, there is always room for ensuring more flexibility and learners' autonomy. This can be done by providing self access learning opportunities to the learners and the instructors need to adjust themselves to the learners' choice as quickly as possible. All these may lead to a more successful way of integrating CLT and CALL in Bangladesh and other EFL contexts.

\section{References}

Bachman, L. F., \& Palmar, A. S. (Eds). (1984). Some comments on the terminology in the Language testing. Communicative competence approaches to language proficiency assessment: Research and application. Avon: Multilingual Matters Ltd.

Begum, R. (2011). Prospect for cell phones as instructional tools in the EFL classroom: A case study of Jahangirnagar University, Bangladesh. English Language Teaching, 4(1), 105-115.

Communicative English: Training manual. (2009). FLTC, Directorate of Secondary and Higher Education, Dhaka.

Gunduz, N. (2005). Computer assisted language learning. Journal of Language and Linguistic Studies, 1(2), 193-214. Retrieved from http://jlls.org/Issues/Volume1/No.2/nazligunduz.pdf

Deb. S. (2000). Effective distance learning in developing countries using mobile and multimedia technology. International Journal of Multimedia and Ubiquitous Engineering, 6(2), 34-40.

Deb. S. (2012). Multimedia technology and distance learning using mobile technology in developing countries. In S. Deb (Ed.), Advanced topics in multimedia research. http://www.dx.doi.org/10.5772/2657 
Hoque, S. M., \& Alam, S. M. (2010). The Role of Information and Communication Technologies (ICTs) in delivering Higher Education -A case of Bangladesh. International Education Studies, 3(2), 97-106.

Hardisty D., \& Windeatt S. (1989). CALL. Oxford: Oxford University Press.

Howatt, A. (1984). A History of English Language Teaching. Oxford: OUP.

Hedge, T. (2000). Teaching and learning in the language classroom. Oxford University Press.

Hymes, D. H. (1972). In Pride, \& Holmes (Eds.), On Communicative Competence. pp. 269-293.

Jones C., \& Fortescue S. (1987). Using computers in the language classroom. Harlow: Longman.

Kiato S. Katheleen, \& Kiato, K. (1996). Testing Communicative Competence. The TESOL Internet Journal, 2(5).

Littlemore J. (2002). Setting up a course in ICT for Language Teachers: some essential considerations. CALL-EJ Online, 4(1).

Littlewood, William. (1981). Communicative Language Teaching. Cambridge: Cambridge University Press.

Maley A. (1989). Down From The Pedestal: Literature as Resource. Literature and the Learner :Methodological Approaches. Cambridge: Modern English Publishers.

M. Mahruf C. Shohel, \& Adrian Kirkwood. (2012). Using technology for enhancing teaching and learning in Bangladesh: challenges and consequences. Learning, Media and Technology, iFirst article, 1-15. http://www.dx.doi.org/ 10.1080/17439884.2012.671177

McNamara, T. (2000). Language Testing. Oxford: OUP.

Richards, J. C., \& Rogers, T. S. (1986). Approaches and methods in language teaching: A description and analysis. Cambridge, UK: Cambridge University Press.

Rogers, T. (2001). Language teaching methodology. Retrieved January, 2010, from, http://www.cal.org/resource/digest/rodgers.html

Seedhouse, P. (1995). Communicative CALL: focus on the interaction produced by CALL software. ReCALL, 7. http://dx.doi:10.1017/S0958344000003906

Underwood J. (1984). Linguistics, computers and the language teacher: a communicative approach. Rowley, MA: Newbury House.

Warschauer M. (1996). Computer Assisted Language Learning: an introduction. In Fotos S. (ed.), Multimedia language teaching. Tokyo: Logos International. pp. 3-20.

Widdowson, H. G. (1978). Teaching language as communication. Oxford: Oxford University Press.

Wright, S. (2000). Community and Communication: The role of language in nation state building and European integration. Clevedon: Multilingual Matters.

\section{Appendix 1: Questionnaire for course participants}

This questionnaire gives a participant the opportunity to express his/her views about the course taken at FLTC. Your responses will be totally anonymous. (Please answer all questions. Tick one box only to answer each question.)

1. How suitable was the course content for you?

not suitable partly suitable mostly suitable suitable very suitable

2. How relevant were the topics covered during the course?

not suitable partly suitable mostly suitable suitable very suitable

3. How user friendly was the digital contents for you?

too difficult difficult partly difficult easy very easy

4. Did the course progress logically from beginning to the end?
yes, always
most of the time
not always
never

5. What were your objectives behind taking this course?

developing speaking fluency

getting job abroad

getting jobs locally

developing overall English competence learning English for higher studies 
6. How much of your objectives have been achieved from the course?
very well
mostly
not much
not at all

7. Was there a balance of lectures, group work and lab-based works in each lesson?
yes, always
most of the time
not always
never

8. Were the course materials available? : (eg reading lists, handouts, etc?
yes, always
most of the time
not always
never

9. Were the course materials useful?
of no use
of little use
of some use
useful
very useful

10. Was the presentations clear enough to understand?
yes, always
most of the time
not always
never

11. Did you find interest in the course?
yes, always
most of the time
not always
never

12. Did the instructor encourage your participation in the class?
never
sometimes
usually
most of the time
always

13. Was the instructor skilled in using the language lab/technology?
never
sometimes
usually
most of the time
always

14. Did the instructor show a good command of the course materials?
never
sometimes
usually
most of the time
always

15. Overall, what do you think of the course content?
very poor
poor
average
good
very good

16. Overall, how well organized was the course?

$\begin{array}{llll}\text { very poor } & \text { poor } & \text { average } & \text { good }\end{array}$

17. What was the overall standard of teaching?

$\begin{array}{llll}\text { very poor } & \text { poor } & \text { average vood good }\end{array}$

18. What is your overall evaluation of the course?

$\begin{array}{llll}\text { very poor } & \text { poor } & \text { average vood good }\end{array}$

19. What is your opinion on the good side(s) of this course?

20 . What is your opinion on the poor side(s) of this course?

21. Please, give suggestions on how to improve this course. 